\title{
Predicting energy consumption of buildings based on their geometrical properties using artifical neural network
}

DOI: $10.46932 / \mathrm{sfjdv} 2 \mathrm{n} 1-062$

Received in: November 1st, 2020

Accepted in: December 30th, 2020

\author{
Todorka Samardzioska \\ $\mathrm{PhD}$, Full Professor \\ (Corresponding author)
}

Ss. Cyril and Methodius University in Skopje

Faculty of Civil Engineering 24, Partizanski Odredi blvd, Skopje, Macedonia

E-mail: samardzioska@gf.ukim.edu.mk

\section{Valentina Zileska Pancovska}

PhD, Full Professor

Ss. Cyril and Methodius University in Skopje

Faculty of Civil Engineering 24, Partizanski Odredi blvd, Skopje, Macedonia

E-mail: valentinazp@gf.ukim.edu.mk

\section{Silvana Petrusheva}

$\mathrm{PhD}$, Full Professor

Ss. Cyril and Methodius University in Skopje

Faculty of Civil Engineering 24, Partizanski Odredi blvd, Skopje, Macedonia

E-mail: silvana@gf.ukim.edu.mk

\section{Maja Gosheva}

assistant

Ss. Cyril and Methodius University in Skopje

Faculty of Civil Engineering 24, Partizanski Odredi blvd, Skopje, Macedonia

E-mail: maja.gosheva@gmail.com

\section{Mihail Naumovski}

assistant

Ss. Cyril and Methodius University in Skopje

Faculty of Civil Engineering 24, Partizanski Odredi blvd, Skopje, Macedonia

E-mail: mihail-miki@hotmail.com

\begin{abstract}
Geometrical characteristics of the building have a significant impact on the building energy consumption and the building classification in the appropriate energy class. Therefore, this paper develops a model for prediction of energy consumption of the buildings and the influence of the building shape factor on the building's energy class. The input for the model was building geometrical parameters: 1) shape factor and 2) areas of the building envelope components, i.e. the areas of: walls, windows, floor, roof and the heated area. In that manner, material properties are neglected for this analysis in order to investigate the influence of dimensions and shapes only on the building energy class. The model uses data of 58 analysed buildings in total. After testing several predictive models, General Regression Neural Network (GRNN) from the predictive modelling software DTREG has been chosen as the most suitable and with most accurate prediction. The mean absolute percentage error is MAPE $=4.7 \%$, coefficient of determination $\mathrm{R}^{2}=89.22$ (which presents the general fit of the model), and the coefficient of correlation is 0.945 . It is concluded that the model gives satisfactory accuracy for predicting the energy consumption of buildings based on their
\end{abstract}


geometrical properties. Regarding the heat transmission function through the building envelope, the smaller the shape factor is, the less is the need for heating/cooling.

Key words: Building, geometrical properties, energy efficiency, artificial neural network.

\section{INTRODUCTION}

One of the goals for sustainable development of each country is efficient energy consumption (Jones et al., 2013; Simovski, 2018; Trpevski, 2010). Therefore, particular attention is put on non-productive sectors (Farhat et al., 2014; Miceli, 2013), such as existing buildings, due to their big participation in energy consumption and $\mathrm{CO}_{2}$ emissions. (De la Cruz - Lovera et al., 2017; Jones et al., 2013; Sunikka - Blank and Galvin, 2012). In fact, buildings are globally named as one of the biggest consumers of energy and yearly $\mathrm{CO}_{2}$ emission per capita (Farhat et al., 2014; Robinson et al., 2016; Smith, 2010).

The above statement in Macedonia is supported by the statistical report of the International Energy Agency, which indicates that the final consumption of electricity in the residential sector represents $47.4 \%$ of the total final consumption of electricity in 2015 in Macedonia. Hence, improving energy efficiency of residential buildings could result with energy consumption decreasing, cost savings, increasing living comfort quality, etc. (Chappells and Shove, 2005; Grueneich, 2015; Sorell, 2015; Thyer et al., 2018).

Public policies are of key importance for buildings' energy efficiency (Kivimaa and Maetiskainen, 2018). In that relation, increasing the energy efficiency of residential buildings has a high priority in Republic of Macedonia (Strategy for energy development, 2010). Energy efficiency policy is achieved through measures and activities for efficient energy usage, such as: 1) adoption of programs and plans for improvement and advancement of energy efficiency and their implementation, 2) performance of services for energy efficiency and energy controls, as well as through 3) fulfilling the obligations of the public sector in terms of energy efficiency and energy conservation.

Design of the building is starting stage in considering building energy efficiency (Farhat et al., 2014). In fact, numerous and different measures can be incorporated in design that determine the building energy class. Some of them are: implementation of systems based on renewable energy, energy management systems usage, using local materials etc. (Farhat et al., 2014; Kialashaki, 2018; Rasool et al., 2015; Wong and Fan, 2013). Also, energy monitoring is of great importance for energy savings (Hanak et al., 2013). Furthermore, for energy efficiency of the building not only the building' type and building shape, but other factors are also relevant, such as: wind, climate, location, residents' lifestyle, residents' habits about energy consumption, etc. (Amber et al., 2017; Akadiri et al., 2013; Hsueh and Yan, 2011). Therefore, researcher' focus of investigation are always some aspects related to the buildings' energy efficiency.

The design process of the building should be with usage of Building Information Modelling (Jansson et al., 2013). That enables transparency among projects participants regarding energy performances of 
alternative buildings designs. This is relevant not only for new building projects, but also for buildings revitalization projects (due to introduction of energy saving measures in order to achieve the EU objectives for energy).

During the design process, the shape of the building is investigating due to its impact on energy consumption and final classification in the appropriate energy class of the building. With regard of that, this paper is focused on investigating energy efficiency of buildings, depending on their basic geometrical properties. The aim of the paper is to develop a sufficiently accurate model for prediction of energy consumption as a function of particular building geometrical parameters, i.e. parameters that can be easily obtained from the technical documentation or measured at the building site.

In this paper, several forms of buildings are compared, and the influence of their form factors on energy classes is analysed.

\section{LITERATURE REVIEW}

Energy efficiency of buildings is among the topics that initiate great researches interest, so there are investigations related to different aspects of the topic (Diakaki et al., 2010, Hsueh and Yan, 2011; Li et al., 2017; Menezes et al., 2014). For the investigations, as widely use traditional methods/techniques are statistical and numerical methods (Amber et al., 2017). But, there are cases where their application is limited due to big number of influencing energy efficiency factors and their changeability. In that cases more sophisticated methods, such as artificial neural networks (ANNs) are used (Dong et al., 2018; Gonzales and Zamarreno, 2005; Kalogirou, 2000; Kumar, et al., 2013; Vakili et al., 2015). One of the reasons is their high accuracy that had been shown in energy efficiency modelling (Arida et al., 2016). In addition, prediction with ANNs is faster than using traditional methods (Dong et al., 2018). Whatever, which method is chosen, researches statement is that real data are used as input (Fiorelli, 2008; Hartungi and Jiang, 2012).

Dong et al. (2018) investigated costs for the energy consumption. Using ANNs for modelling, they have shown that ANN that had multiple outputs had more accurate prediction than ANN with one output. Among the variables was the form of the building.

The authors Neto and Fiorelli (2008) have made a comparison between a simple model based on ANN and a model that is based on physical principles in order to predict the building energy consumption and they showed that both models are suitable. Similar, Ekici and Aksoy (2009) and Holcomb et al. (2009) proved that ANN can be used for predicting energy needs by the building with satisfactory accuracy. Furthermore, the study of Ahmad et al. (2014) compared the accuracy of ANN and support vector machine and suggested that development of hybrid models are useful for predicting the building electrical energy.

Although the building usage of energy is investigated by different aspects of many researches, additional investigation are needed in order to cover all aspects for achieving optimal energy performances of the buildings (Hanak et at., 2013; Jawdeh, et al., 2010; Summerfield and Lowe, 2012). Therefore, this 
paper aims to develop a model for predicting the building energy loses through the building envelope using real historical data and an intelligent technique - artificial neural network (NN).

\section{RESEARCH METHODOLOGY}

\subsection{SAMPLE}

In this research, data for 58 real-designed buildings have been collected as necessary data for developing a model for energy consumption and, furthermore the building classification in the energy class that is appropriate.

In order to reach the ultimate goal, the buildings are divided into two groups, residential and commercial buildings, and then in appropriate subgroups, depending on the size of the heated area.

Furthermore, due to examination of the influence of the shape factor on the energy class, for all the elements of the building envelope (floor, walls, windows and roof), a unique way of thermal insulation is adopted. All buildings are assumed to be with same construction of the façade, windows and doors of the same quality, as well as the same construction of the floors and roofs. This means that the same heat transfer coefficients (so called U-coefficients) for the floors, walls, windows and roofs are respectively adopted for all buildings, i.e. the maximum allowed in the Rulebook on energy characteristic of buildings (2013).

Input parameters for developing the model were: 1) the shape factor $f_{0}$, and 2) the areas of the building envelope components: Area of walls - $A_{w a l l}$, Area of windows - $A_{\text {window }}$, area of floor - $A_{\text {floor }}$, area

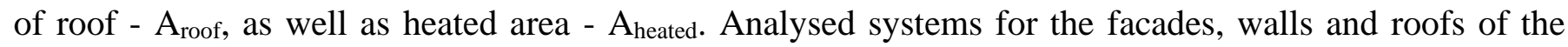
buildings satisfy the minimum requirements for energy efficiency, stated in the Rulebook (2013), i.e. have the maximum allowed values for their U-coefficients. In order to investigate the influence of the dimensions and shape only on the building's energy class, the model neglects the material properties.

\subsection{METHOD}

\subsubsection{Artificial neural networks as soft computing methods}

In the last 3 decades the methodology of neural networks (NN) was adopted by the research community in every branch of civil engineering, demonstrating very successful applications, providing convenient and in most of the cases very accurate solutions to the problems.

NNs are soft computing methods which are universal nonlinear functional approximators. They consist of many interconnected processing elements (neurons) and they are biologically inspired computational models which implement functioning of the human neurons. Using a set of input data and performing input-output mapping, they produce a set of output, using some predetermined mapping rule implemented in their structure. The neurons take the input either externally or from the other neurons and pass it through some activation function (kernel function). Data enter the NN through the so called input layer of neurons and after the processing in the input layer they are fed forward through successive layers to 
the output layer. The input data can be any set of variables that are important and most representative for predicting the output variable (so called target variable). Variables which are used for predicting the target variable are called predictors.

The NN which is used is trained to learn the relationship in the data, minimizing the error between the actual output values and predicted values.

There are many different types of NN's depending on the architecture and training algorithms, developed for solving different kind of problems (Kecman, 2001).

In this research, after testing several other predictive models, the general regression neural network (GRNN) has been chosen, which was most suitable for our kind of data, presenting most accurate prediction.

\subsubsection{General regression neural network}

GRNN has been proposed by Specht (1991). This NN has highly parallel structure and can be used for mapping, prediction, as a controller, for classification and as a good solution for online dynamic system (their control and system identification).

GRNN converges to the optimal solution very fast, because it needs only several training samples, this makes it very useful in many applications, specifically with sparse data. Some other advantages of GRNN are its quick training approach, i.e. it learns in single pass and no back propagation is needed, and also it is very accurate because of the usage of the Gaussian function as kernel function. Also, it can work with noisy input data. The main disadvantage for this $\mathrm{NN}$ is that it can grow to great size requiring big memory space, making it computationally expensive.

Mathematical representation of GRNN is given in eq. (1)

$$
Y(X)=\frac{\sum_{k=1}^{n} y_{k} e^{\left(-D_{k} / 2 \sigma^{2}\right)}}{\sum_{k=1}^{n} e^{\left(-D_{k} / 2 \sigma^{2}\right)}}
$$

where $D_{k}=\left(X-X_{k}\right)^{T}\left(X-X_{k}\right)$ is the Euclidean distance between the input $\mathrm{X}$ and the training samples $\mathrm{X}_{\mathrm{k}}$. $\square \square$ is smoothing parameter of GRNN.

The architecture of GRNN is shown in Fig. 1. The input layer has number of neurons equal to the number of predictors and the neurons from every layer feed the processed values of input variables to the neurons from the next layer. There are 4 layers of neurons. The last layer is decision layer where the output (predicted value) is obtained. 
Fig. 1 GRNN architecture

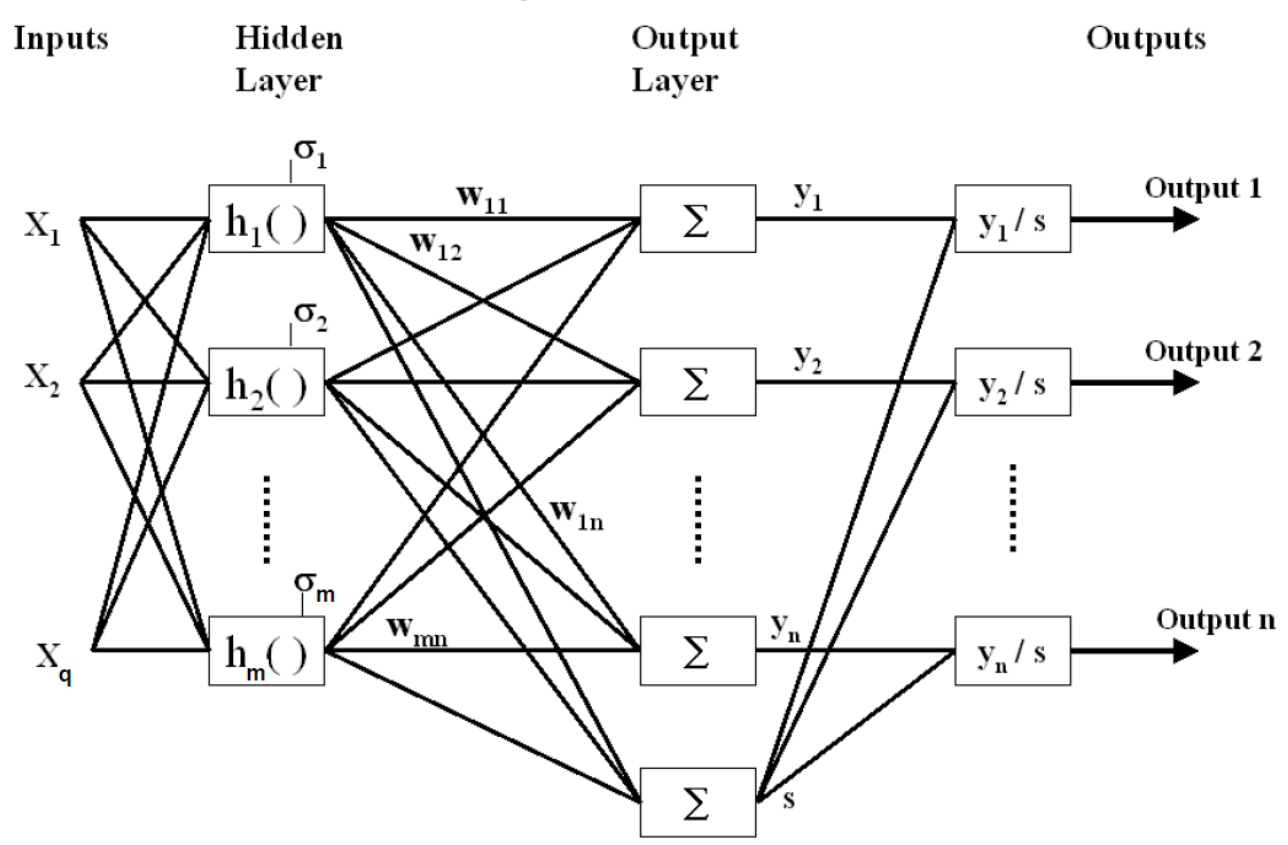

\section{RESULTS AND DISCUSSION}

In this paper, the predicting modelling software DTREG (Sherrod, 2013) is used for predicting the energy consumption $Q$ from 12 variables. The following variables are used as the most influential: type of building, shape factor $-\mathrm{f}_{0}$, heated area - $\mathrm{A}_{\text {heated, }}$, area of the building envelope - $\mathrm{A}_{\text {envelope, }}$ total net area of walls - $\mathrm{A}_{\text {wall, }}$, total area of windows - $\mathrm{A}_{\text {window }}$, area of roof - $\mathrm{A}_{\text {roof, }}$ area of floor - $\mathrm{A}_{\text {floor }}$, and corresponding heat transfer coefficients $\mathrm{U}_{\text {wall }}, \mathrm{U}_{\text {window }}, \mathrm{U}_{\text {roof }}$ and $\mathrm{U}_{\text {floor. }}$.

General regression neural network (GRNN) from the software DTREG is used as most suitable model for prediction. Before entering the GRNN, the data has been normalized on the interval $[1,2]$. The accuracy of the prediction is measured by the most standard predictive parameters: MAPE (mean absolute percentage error) and $\mathrm{R}^{2}$ - the coefficient of determination which reflects the general suitability of the model. For the validation data, MAPE for our developed model is $4.75 \%$ and $\mathrm{R}^{2}$ is $89.22 \%$. The coefficient of correlation between actual and predicted values of the target variable Q is 0.945 . The results for the most important parameters for the accuracy for the training and validation data are given in Table 1.

DTREG software computes overall importance of the variables which contribute the most for the accuracy of the model, and from where can be obtained some valuable conclusions about the consumption of the energy. Their level of importance is given in Table 2.

Table 1. Training and validation data

--- Training Data ---
Mean target value for input data $=1.3793793$
Mean target value for predicted values $=1.3774421$


Variance in input data $=0.0674536$

Residual (unexplained) variance after model fit $=0.0049109$

Proportion of variance explained by model $\left(\mathrm{R}^{\wedge} 2\right)=0.92720(92.720 \%)$

Coefficient of variation $(\mathrm{CV})=0.050804$

Normalized mean square error $(\mathrm{NMSE})=0.072803$

Correlation between actual and predicted $=0.963445$

Maximum error $=0.266849$

RMSE (Root Mean Squared Error) $=0.0700775$

MSE (Mean Squared Error) $=0.0049109$

MAE (Mean Absolute Error) $=0.042832$

MAPE (Mean Absolute Percentage Error) $=2.9658621$

\section{--- Validation Data ---}

Mean target value for input data $=1.3793793$

Mean target value for predicted values $=1.3821067$

Variance in input data $=0.0674536$

Residual (unexplained) variance after model fit $=0.0072743$

Proportion of variance explained by model $\left(R^{\wedge} 2\right)=0.89216(89.216 \%)$

Coefficient of variation $(\mathrm{CV})=0.061832$

Normalized mean square error $(\mathrm{NMSE})=0.107842$

Correlation between actual and predicted $=\mathbf{0 . 9 4 4 7 9 1}$

Maximum error $=0.266849$

RMSE (Root Mean Squared Error) $=0.0852896$

MSE (Mean Squared Error) $=0.0072743$

MAE (Mean Absolute Error) $=0.0645952$

MAPE (Mean Absolute Percentage Error) = 4.7503939

Table 2. Overall importance of variables

\begin{tabular}{|c|c|}
\hline Variable & Importance \\
\hline norm- $f_{0}$ & 100.000 \\
\hline Norm - $\mathrm{A}_{\text {floor }}$ & 26.588 \\
\hline NORM - $\mathrm{A}_{\text {roof }}$ & 25.777 \\
\hline Norm- $A_{\text {window }}$ & 22.338 \\
\hline Building & 2.123 \\
\hline Norm- $A_{\text {wall }}$ & 0.112 \\
\hline Norm-A $A_{\text {heated }}$ & 0.091 \\
\hline
\end{tabular}

DTREG has option for improving the accuracy of the model by reducing the number of neurons of the GRNN. By using that option the number of neurons was reduced to 29 neurons and the accuracy of our model was improved by retraining. Removing unnecessary neurons has some benefits, and some of them are that the size of the memorized model is reduced and removing neurons often improves the accuracy of the model (Sherrod, 2013b).

For every numerical variable DTREG computes its minimal, maximal, mean value and standard deviation (Table 3).

Table 3. Minimal, maximal, mean value and standard deviation for all numerical variables

\begin{tabular}{|c|c|c|c|c|c|}
\hline \multicolumn{6}{|l|}{ Continuous Variables } \\
\hline Variable & \# Rows & Minimum & Maximum & Mean & Std. Dev. \\
\hline
\end{tabular}




\begin{tabular}{|c|c|c|c|c|c|}
\hline \multicolumn{6}{|c|}{ 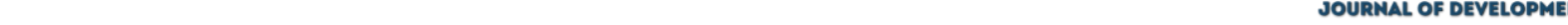 } \\
\hline Norm- $A_{\text {heated }}$ & 58 & 1.00000 & 2.00000 & 1.10198 & 0.16791 \\
\hline Norm-A $\mathrm{A}_{\text {envelope }}$ & 58 & 1.00000 & 2.00000 & 1.11330 & 0.16066 \\
\hline norm-f0 & 58 & 1.00000 & 2.00000 & 1.47440 & 0.22804 \\
\hline Norm- $A_{\text {wall }}$ & 58 & 1.00000 & 2.00000 & 1.17062 & 0.19932 \\
\hline Norm - $\mathrm{U}_{\text {wall }}$ & 58 & 1.00000 & 1.00000 & 1.00000 & 0.00000 \\
\hline Norm- $A_{\text {window }}$ & 58 & 1.00000 & 2.00000 & 1.15426 & 0.20179 \\
\hline Norm- $U_{\text {window }}$ & 58 & 2.00000 & 2.00000 & 2.00000 & 0.00000 \\
\hline NORM - $A_{\text {roof }}$ & 58 & 1.00000 & 2.00000 & 1.08838 & 0.15274 \\
\hline NORM-U roof & 58 & 1.00000 & 1.00000 & 1.00000 & 0.00000 \\
\hline Norm - $\mathrm{A}_{\text {floor }}$ & 58 & 1.00000 & 2.00000 & 1.08478 & 0.15168 \\
\hline Norm-U $\mathrm{U}_{\text {floor }}$ & 58 & 1.00000 & 1.00000 & 1.00000 & 0.00000 \\
\hline
\end{tabular}

The model was tested also with another 3 predictive models: SVM (support vector machine, MLP (multilayer perceptron) and RBF NN (radial basis function neural network) in order to obtain the most accurate predicting. The results for the accuracy presented by the MAPE, R2 and the coefficient of correlation between actual and predicted target values, for all 4 predictive models are given in Table 4 .

Table 4. Comparison of the accuracy for the 4 tested models

\begin{tabular}{|l|c|c|c|}
\hline $\begin{array}{l}\text { Predictive } \\
\text { model }\end{array}$ & MAPE $(\boldsymbol{\%})$ & $\mathbf{R}^{2}(\boldsymbol{\%})$ & $\begin{array}{c}\text { Coefficient of correlation between actual } \\
\text { and predicted target values }\end{array}$ \\
\hline GRNN & 4.75 & 89.22 & 0.945 \\
\hline SVM & 6.26 & 80.93 & 0.900 \\
\hline MLP & 6.04 & 79.18 & 0.909 \\
\hline RBF NN & 7.61 & 60.49 & 0.821 \\
\hline
\end{tabular}

The most accurate prediction was obtained with GRNN, and the chart for the dependences between actual and predicted target values is shown on Fig.2 (Sherrod, 2013)

Fig2 . Chart of actual and predicted target values (Sherrod, 2013 a).

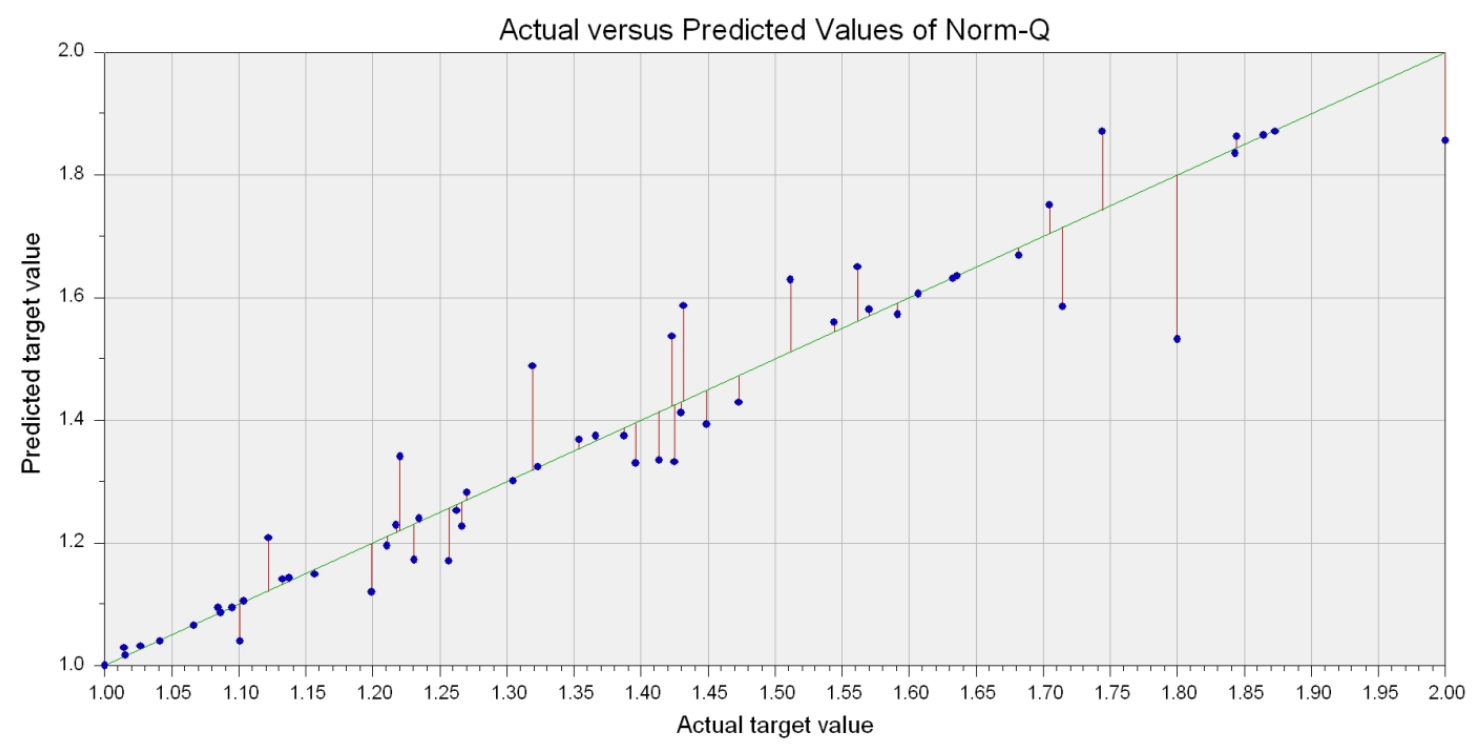

Because thermal transmission losses are proportional to the surface of the building envelope, the more compact the shape, the lower the heat losses. Compactness is defined as the ratio of the volume and 
the area of the building envelope. On the other hand, several studies show that buildings with a smaller shape factor value, which represents a reciprocal value of compactness, are optimal for hot and dry regions. The variation of the outdoor temperature has smaller influence on a smaller building envelope. Therefore, the heating losses and the required energy for heating/cooling of the building are smaller.

We can conclude that the data from building energy system can be modelled very well with ANN, specifically with GRNN, which can handle with noisy data, because predicting the behaviour of building energy system requires modelling multivariate non-linear relationships and very often the variables are from noisy environment. Many variables are involved in the modelling and prediction of the energy efficiency in buildings, and the exact interactions between them are not fully understood, or cannot be modelled very easy. In addition, there are not enough mathematical formulas which will explain the relationship between the variables involved. Also, the performances of the building energy system depends on environmental conditions like wind speed, its direction, duration and intensity, also solar radiation, and this conditions are very changeable. Due to all these reasons, modelling building energy systems is a kind of a problem for which NN approach, i.e. data-driven approach, appears to be most applicable (Kalogirou, 2006).

The authors Ben-Nakhi and Mahmoud (2004) have used GRNN to optimize HVAC (heating, ventilating and air-conditioning) thermal energy storage in office and public buildings. External temperature readings for every hour for a 24 hour period have been used as input data and output was the hourly cooling load for the next day. The performances of GRNN expressed by $\mathrm{R}^{2}$ have shown that properly designed GRNN is powerful instrument for optimizing thermal energy storage in buildings, using only external energy records.

Lee et al. (2004) have used GRNN for detecting and diagnosing faults in Air Handling Unit (AHU) at the subsystem level. The parallel structure of GRNN makes it useful for real-time fault detection and diagnosis. The results have shown that GRNN is accurate and reliable estimator of highly non-linear and complex AHU processes.

\section{CONCLUSION}

Energy losses through the building envelope can be reduced using suitable measures in the building design and hence the building energy class can be improved. In that process, a special attention should be paid on many building parameters which contribute to the energy consumption. Therefore, having a simplified model for prediction of the building energy consumption, which uses only geometrical parameters as input data, is of designers' interest firstly.

The model presented in this paper uses the most relevant parameters of the building geometry for 58 buildings as input, such as: shape factor, areas of the walls, roofs, floors and windows, heated area etc. The GRNN was used as ANN for developing the model. It is concluded that GRNN is suitable for prediction of energy loses through the building envelope (the general fit of the model is $\mathrm{R} 2=89.22$, the MAPE$=4.7 \%$ 
(the mean absolute percentage error) and the coefficient of determination is 0.945 .

From this point of view, the results of this research may become important because it combines the analysis of several parameters that have good prospects for the basic configuration of the building and the decisions for the building envelope, taken in the early stages of the design process. In addition, the results of the simulation of the examined archetypes provide a prediction of the annual use of energy in their operational phase. If the building's design in its preliminary phase is guided by future energy performance, it will in essence help designers to contribute to environmental sustainability.

The archetypes analysed in this paper are with basic geometry, but the results can also be applied to a variety of other building configurations. Using the results of a comprehensive parametric analysis, correlation develops, by means of which one can predict the impact of the shape of the buildings on their energy efficiency. 


\section{REFERENCES}

Ahmad S. A., Hassan Y. M., Abdullah P. M., Rahman A. H., Hussin F., Abdullah H., Saidur, R. (2014). A review on applications of ANN and SVM for building electrical energy consumption forecasting. Renewable and Sustainable Energy Reviews, 33. pp. 102-109. https://doi.org/10.1016/j.rser.2014.01.069

Akadiri O. P., Olomolaiye O.P., Chiniyo E. (2013). Multi-criteria evaluation model for the selection of sustainable materials for building projects. Available at: https://www.researchgate.net/publication/233902961_Multi-

criteria_evaluation_model_for_the_selection_of_sustainable_materials_for_building_projects

Amber K. P., Aslam M.W., Mahmood A., Kousar A., Younis M.Y., Akbar B., Chaudhary G.Q., Hussain S. K. (2017). Energy Consumption Forecasting for University Sector Buildings. Energies, 10,1579. pp.1-18. doi:10.3390/en10101579

Arida M., Nassif N., Talib R., Abu - Lebdeh T. (2016). Building Energy Modeling Using Artificial Neural Networks. Energy Research Journal, 7(2). pp. 24-34. DOI: 10.3844/erjsp.2016.24.34

Ben-Nakhi A. E. and Mahmoud M. A. (2004). Cooling load prediction for buildings using general regression neural networks. Energy Conversion and Management, 45(13-14). 2127-2141.

Chappells H., Shove E. (2005). Debating the future of comfort: environmental sustainability, energy consumption and the indoor environment. Available at: https://www.tandfonline.com/doi/abs/10.1080/0961321042000322762

De la Cruz - Lovera K., Perea - Monero A.-J., De la Cruz - Fernandez J.-L., Alvarez - Bermejo J. A., Manzano - Agugliaro F. (2017). Worldwide Research on Energy Efficiency and Sustainability in Public Buildings. Available at: https://www.mdpi.com/2071-1050/9/8/1294

Diakaki C., Grigoroudis E., Kabelis N., Kolokkotsa D., Kalaitzakis K., Stavrakis G. (2010). A multi objective decision model for the improvement of energy efficiency in buildings. Available at: https://www.sciencedirect.com/science/article/abs/pii/S0360544210002756?via\%3Dihub

Dong Q., Xing K., Zhang H. (2018). Artificial Neural Network for Assessment of Energy Consumption and Cost for Cross Laminated Timber Office Building in Severe Cold Regions. Sustainability, 10(84). pp. 1-15. doi:10.3390/su10010084

Ekici B. B., Aksoy T. U. (2009). Prediction of building energy consumption by using artificial neural networks. Advances in Engineering Software, 40(5). pp. 356-362. https://doi.org/10.1016/j.advengsoft.2008.05.003

Farhat R., Ghaddar K. N., Ghali K. (2014). Investing in PV systems utilizing savings from building envelop replacement by sustainable local material: a case study in Lebanese inland region. International Journal of Energy Economics and Policy. 4(4), pp.554-567. Available at: http://www.econjournals.com/index.php/ijeep/article/view/898

Gonzales A. P., Zamarreno M. J. (2005). Prediction of hourly energy consumption in buildings based on a feedback artificial neural network. Energy and Buildings, 37(6). pp. 595-601.

Grueneich M. D. (2015). The Next Level of Energy Efficiency: The Five Challenges Ahead. Available at: https://www.sciencedirect.com/science/article/pii/S104061901500144X

Hanak T., Vukomanovic M., Radujkovic M. (2013). Economic evaluation of energy - saving measures on 
panel buildings in the Czech Available at: https://www.researchgate.net/publication/287616749_Economic_evaluation_of_energysaving_measures_on_panel_buildings_in_the_Czech_Republic_

Hartungi R., Jiang L. (2012). Energy efficiency and conservation in an office building: a case study. Available at: https://www.emeraldinsight.com/doi/abs/10.1108/17506221211242059_

Holcomb D., Li W., Seshia A. S. (2009). Algorithms for Green Buildings: Learning-Based Techniques for Energy Prediction and Fault Diagnosis. Electrical Engineering and Computer Sciences. University of California at Berkeley Technical Report No. UCB/EECS-2009-138 University of California at Berkeley. http://www.eecs.berkeley.edu/Pubs/TechRpts/2009/EECS-2009-138.html

Hsueh S. - L., Yan M. - R. (2011). Enhancing Sustainable Community Developments: A Multi-criteria Evaluation Model for Energy Efficient Project Selection, Energy Procedia, 5, pp. 135-144. doi:10.1016/j.egypro.2011.03.025

Jansson G., Schade J., Olofsson T. (2013). Requirements management for the design of energy efficient buildings. Building Research \& Information, 41(5). pp. 532-550. DOI: 10.1080/09613218.2013.807064. Availible at: https://www.itcon.org/paper/2013/16

Jawdeh B. H., Wood G., Abdul - Malak, A. M. (2010). Altering Design Decisions to Better Suit Facilities Management Processes. Tenth International Conference for Enhanced Building Operations, Kuwait, Proceedings. pp. 1-7. http://usir.salford.ac.uk/23054

Jones P., Lannon S., Patterson J (2013). Retrofitting existing housing: how far, how much? Available at: https://www.tandfonline.com/doi/abs/10.1080/09613218.2013.807064

Kalogirou S. A. (2000). Applications of artificial neural-networks for energy systems. Available at: https://www.researchgate.net/publication/280806206_Applications_of_artificial_neural-

networks_for_energy_systems

Kalogirou A. S. (2006). Artificial neural networks in energy applications in buildings. International Journal of Low Carbon Technologies. 1(3), pp. 201-216.

Kecman V. (2001). Learning and Soft Computing: support vector machines, neural networks and fuzzy logic models. A Bradford Book. The MIT Press, Cambridge, Massachusetts, London, England.

Kialashaki, Y. (2018). A linear programming optimization model for optimal operation strategy design and sizing of the CCHP systems. Energy Efficiency, 11(1). Pp. 225-238

Kivimaa P., Martiskainen M. (2018), Innovation, low energy buildings and intermediaries in Europe: systematic case study review. Energy Efficiency, 11(1), pp 31-51. DOI 10.1007/s12053-017-9547-y

Kumar R., Aggarwal R.K., Sharma J.D (2013). Energy analysis of a building using artificial neutral network: A review. Energy and Buildings, 65. pp. 352-358. Available at: https://www.sciencedirect.com/science/article/pii/S0378778813003459?via\%3Dihub

Lee W., House J. M. and Kyong N. (2004). Subsystem level fault diagnosis of a building's air-handling unit using general regression neural networks, Applied Energy, 77(2), 153-170.

Li C., Ding Z., Zhao D., Yi J., Zhan, G. (2017). Building Energy Consumption Prediction: An Extreme 
Deep Learning Approach, Energies, 10(1525). pp. 1-20. doi:10.3390/en10101525

Menez A. C., Cripps A., Buswell R. A., Wright J., Bouchlaghem D. (2014). Estimating the energy consumption and power demand of small power equipment in office buildings. Available at: https://www.sciencedirect.com/science/article/pii/S0378778814001224

Miceli R. (2013). Energy Management and Smart Grids. Available at: https://www.mdpi.com/1996$1073 / 6 / 4 / 2262$

Neto H.A., Fiorelli S.A.F. (2008). Comparison between detailed model simulation and artificial neural network for forecasting building energy consumption. Energy and Buildings, 40(12). pp. 2169-2176. https://doi.org/10.1016/j.enbuild.2008.06.013

Rasool Z., Tariq W., Othoman L.M., Jasni J. (2015). What building management system can offer to reduce power wastage both social and economical: Brief discussion by taking malaysian power infrastructure as a sample. The SIJ transactions on industrial, financial \& business management (IFBM), 3(3), pp. 27-31. Available

at:

https://www.researchgate.net/publication/320022293_What_Building_Management_System_Can_Offer_ to_Reduce_Power_Wastage_both_Social_and_Economical_Brief_Discussion_by_Taking_Malaysian_Po wer_Infrastructure_as_a_Sample

Robinson F. J., Foxon J. T., Taylor G. P. (2016). Performance gap analysis case study of a non-domestic building. Proceedings of the Institution of Civil Engineers-Engineering Sustainability, 169(1). pp. 31-38. http://dx.doi.org/10.1680/ensu.14.00055

Sherrod P. (2013a). Predictive modelling software DTREG. www.dtreg.com. Accessed on 16 February, 2018

Sherrod P. (2013b). Predictive modeling software DTREG - tutorial. www.dtreg.com. Accessed on 16 February, 2018

Simovski A. (2018). Sustainable development. The state statistical office, Skopje, Republic of Macedonia. Smith P.F. (2010). Building for changing climate: The challenge of construction, Planning and energy. Available at:

https://www.tandfonline.com/doi/abs/10.1080/13563475.2012.726413?journalCode=cips20

Sorrell S. (2015). Reducing energy demand: A review of issues, challenges and approaches. Available at: https://www.sciencedirect.com/science/article/pii/S1364032115001471?via\%3Dihub

Specht D.F. (1991). A General Regression Neural Network. IEEE Transactions on neural networks. 2 (6). pp. $568-576$.

Summerfield A. J., Lowe R. (2012). Challenges and future directions for energy and buildings research. Available at:

https://www.tandfonline.com/doi/full/10.1080/09613218.2012.693839

Sunikka - Blank M., Galvin R. (2012). Introducing the prebound effect: the gap between performance and actual energy consumption. Available at:

https://www.tandfonline.com/doi/abs/10.1080/09613218.2012.690952

Thyer S., Thomas S., McClintock C., Ridd M. (2018), Optimising energy use in an existing commercial 
building: a case study of Australia's Reef HQ Aquarium. Energy Efficiency, 11(1). pp. 147-168. DOI 10.1007/s 12053-017-9556-X

Trpevski S. (2010). The national strategy of sustainable development. Ministry of environment and physical planning, Skopje, Republic of Macedonia.

Uez P.C., Rauber C., da Silva J.B.V. (2021). Casarão Amália Noll: An architectural mosaic of the immigration in southern Brazil. South Florida Journal of Development, Miami, 2(1).

doi: https://doi.org/10.46932/sfjdv2n1-006

Vakili M., Sabbagh - Yazdi S. - R., Klhor K., Khorojerdi S. (2015). Using Artificial Neural Networks for Prediction of Global Solar Radiation in Tehran Considering Particulate Matter Air Pollution. Energy Procedia, 74. pp. 1205 - 1212. doi: 10.1016/j.egypro.2015.07.764. available at: https://www.sciencedirect.com/science/article/pii/S1876610215015325

Wong K-D., Fan Q. (2013). Building information modeling (BIM) for sustainable building design, Facilities, 31(3/4). pp. 138-157. DOI 10.1108/02632771311299412

Rulebook for energy characteristics of buildings. (2013) Official Gazette of the Republic of Macedonia No 94/2013.

Strategy for energy development in the Republic of Macedonia until 2030. (2010). Ministry of Economy, Government of Republic of Macedonia. 